\title{
Comparative and contrast study of Karbandie's Masonry ribs brick arrangements
}

https://doi.org/10.1515/cls-2020-0013

Received Jun 08, 2020; accepted Sep 16, 2020

Abstract: Karbandies' masonry ribs construction technology is influenced by form and size, on one hand, and traditional architects' creativity, on the other hand. Some of the exclusive characteristics of construction techniques of Karbandies' ribs are revealed, after investigating and identifying of some of traditional construction ways of them, investigating contemporary studies conducted in the field and comparing the methods. The masonry ribs have been built in different forms over time and such different forms result in formation of different construction technologies. The masonry ribs' form and size and the bricks' arrangement way have direct effect on their construction process. The aim of the present paper is to determine construction technology of the masonry ribs used in different Karbandies. Hence, in line with achieving this goal, it also tries to investigate geometric arrangement of bricks in masonry ribs. The present study, for the first time, presents a comparative structure to study different implementation ways of Karbandies' masonry ribs and reasons for similarities and differences among different samples. Moreover, the present study tries to draw implementation way of different types of ribs with the aid of 2D and 3D software and by doing library studies, field understandings and interviewing the related masters and then the collected data were studied, comparatively. Data-gathering of this research included library studies which included written, listening and visual methods of books, articles and dissertations. Interviewing traditional masters, who are expertise in the field, were used in the samples analysis. Then according to the mas-

\footnotetext{
${ }^{\star}$ Corresponding Author: Nima Valibeig: Architectural \& Urban Conservation Department, Conservation \& Restoration Faculty, Art University of Isfahan, Isfahan, Iran; Email: n.valibeig@aui.ac.ir Shahrzad Ainechi: Graduate in Architecture of Urban Conservation, Art University of Isfahan, Isfahan, Iran
}

Article note: This article is taken from the part of the first author's doctoral dissertation entitled "The analysis of the impact of formal structure on the technology of construction and restoration of Karbandi in the Tabriz Bazaar" that advise the author of the second in the Faculty of Arts University of restoration has been done. ter builders' advice, structural form of karbandi ribs was modelled using three-dimensional software type. In this study karbandie's masonry ribs were divided into three categories of radial brick vault, pitched brick vault and a combination of them based on their brick arrangement way. Investigation of the results indicated that the bricks due to their geometrical form and variety in shape can result in various combinations. Different factors including materials, centering, dimensions, bay size and other factors are influential in bricks arrangement of the ribs.

Keywords: Masonry rib, Karbandi rib, Karbandi, Bricks arrangement

\section{Introduction}

There should be a harmony between what is formed of geometry in the architect's mind (theoretical geometry) and what is implemented on the materials (applied geometry). In other words such a torn string should be coalesced again [1]. In ratio of the number of traditional architects, regardless of climatic subjects, and based on the experience and knowledge of executive techniques effective in promoting strength of traditional structures, various methods can be found in construction of vaults and ribs in historical monuments [2]. Iranian architects had to use masonry ribs, mainly, due to lack of appropriate timbers for ceiling the spaces. Thickness, size and structural role of ribs are not equal. The ribs on the longitudinal side receive the main load, hence they are thicker and the ribs on the latitudinal side bear fewer loads and hence they are less thick [3]. Ribs placement mechanism takes place in different ways in the buildings. When these structures are increased or decreased in size, they take various forms with different dimensions, which require various arrangements. Different factors including material,centering, dimensions and size of the bay ... are influential in the masonry ribs arrangement way. The present article will scrutinize effects of such factors on the masonry ribs in a clearer manner. Hence, the following research questions were developed: This work is licensed under the Creative Commons Attribution 4.0 License 
(1) What are the classifications of bricks arrangement manner in the Karbandi masonry ribs?

(2) What are the differences and similarities among different arrangement way of the Karbandi masonry ribs?

(3) What is the connection way of Karbandi ribs together and that of Karbandi masonry ribs?

\section{Review of the related literature}

Various researchers have conducted studies on masonry ribs. Some have done research in the field of numerical structural analysis $[4,7,8]$. This is while some other scholars have investigated strengthening method of masonry ribs [5]. There have been researchers, who had studied stability of masonry buttresses of non-rectangular geometries under horizontal forces [6]. From among the Iranian researchers, some of them have proceeded on studying geometry and bricks arrangement in different vaults and domes $[2,9,10]$. Moreover, some of the foreign researchers have investigated Iranian masonry ribs and vaults relying on the technical and historical approach [11-14]. In a book, Islamic-Iranian era architecture has been presented and explained in details, and such details have been classified systematically based on patterns of masonry ribs and vaults [15]. Demonstrating sample construction of radial brick vault masonry rib in Alchag Mosque of Tabriz [16], and investigation of different ways of brick arrangement in construction of pitched brick vault [17] are among the major researches conducted in this field.

In most of the studies only some brief explanations have been provided on details and construction method of masonry ribs. In this study, Arrangement method of bricks on the karbandie's masonry rib has been studied, for the first time, in different cities. The similarities and differences among various types of brick arrangements are expressed in the following sections of the present study.

\section{Research methodology}

Firstly, the data related to the initial samples were obtained by "direct field observation", "interviewing the craftsmen and repairers of the monuments" and "library studies”. After that, the samples' brick arrangement was implemented through modeling with the aid of 3D software. The samples selection was based on different structural forms of the ribs placement and arrangement. For validity of the study results it was tried to ask several crafts- men's from different generations and different areas in order to clarify different effects of craftsmen's skills and regional style feature on the monument. Finally, the findings related to all samples were analysed to show their differences and similarities.

\section{Theoretical framework of the study}

If an arc is continued in its longitudinal (horizontal) direction so that its depth is not more than its bay, then it is called rib. Masonry rib is a curved beam which is responsible for transferring vault loads to load bearing columns or walls and this is its prominent responsibility [18].

\subsection{Karbandi}

Karbandi is the structural system with intersecting ribs and star-shaped geometry which is considered as the main pattern in the traditional architecture roofs [19]. Its making mechanism is as follows: firstly several main and load bearing ribs are implemented with masonry materials, then the remaining ribs are attached to it. After all intersecting ribs are raised in this way, vaults are established on them [20]. Karbandi is a kind of overlay structure of different architectural bases that has four main parts: 1) Masonry rib 2) Karbandi ribs 3) Fillers 4) Araghchin (a apart of domical vault) (Figure 2).

Some ribs necessarily have a non-90-degree angle. Structures are called karbandies whose ribs skewback are placed lower than arc apex.

Studies show that the karbandi ribs must withstand their load, fillers and araghchin.

Major roles that karbandi plays in the interior spaces:

- Providing the possibility of implementing geometric and three-dimensional pre-planned designs in different openings and dimensions of space.

- Thermal insulation of the interior space.

- Adjust the light and sometimes the sound inside the building.

- Applying the karbandi makes the gravity forces have a regular distribution on the piers. This regular distribution contributes to the uniform distribution of stress in the building to increase the stability of the building. 

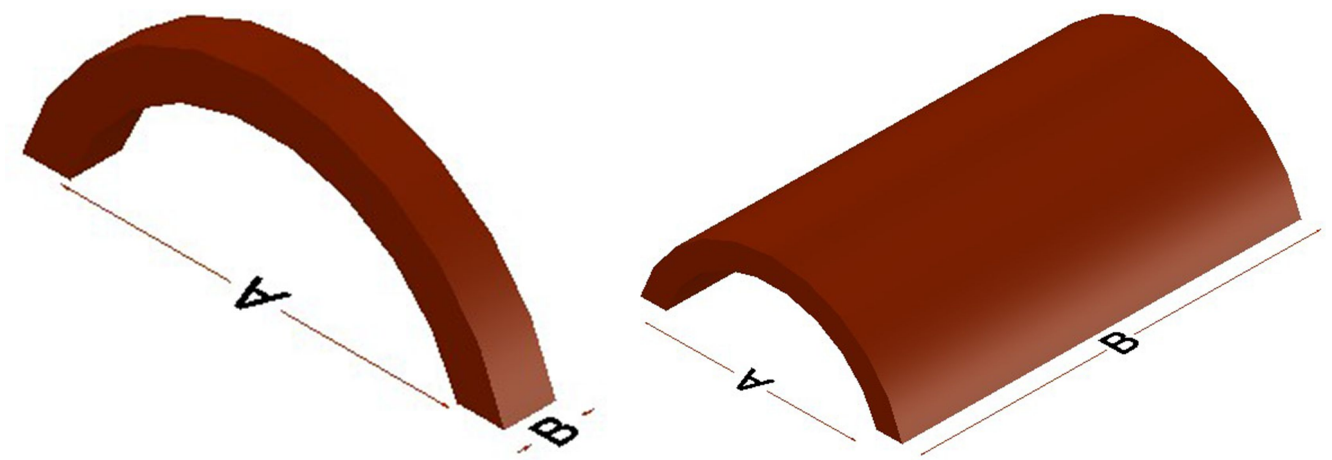

Figure 1: Comparison of vault and rib (authors). Vault $=B>A$ \& $R i b=B<A$

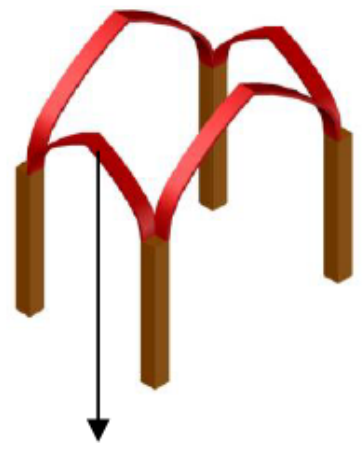

1) Masonry rib

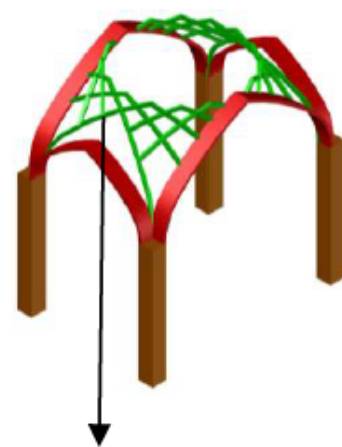

2) karbandi ribs

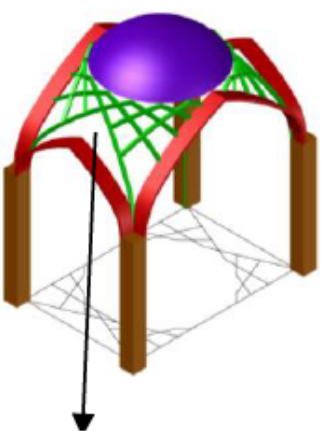

3) Fillers

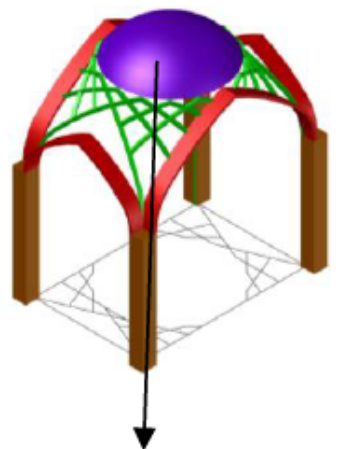

4) Araghchin

Figure 2: Karbandi components(authors).

- In karbandi with the use of masonry ribs and karbandi ribs the loads are directed in specific directions to reach the piers.

- Karbandi is superior to seismic stability in lateral and asymmetric movements compared to most vaults.

\subsection{Three methods of masonry ribs construction}

Load bearer masonry rib is usually implemented in radial brick vault, pitched brick vault and in a combination of these two methods. In the Karbandis, masonry rib is constructed only in pitched brick vault and a mixture of hidden method.

\section{Pitched-brick vaults (vertical brick vault)}

Pitched-brick vaults are type of brickwork that used in the vaults. If the basis of the work will be a $20^{\star} 20^{\star} 5$ centimeters brick, some bricks will be seen in the side view of the arch, of which the 5 centimeters side in the first row will be placed on the Impost and the 20 centimeters side moves along with the arch curve (Shiner arrangement).

\section{Tile vault brick work}

Radial brickwork vaults are type of brickwork that used in the vaults. In this type of brickworks, the bricks are used horizontally. Rectangle $20 \mathrm{~cm}^{\star} 5 \mathrm{c} \mathrm{m}$ is seen from front view (stretcher arrangement).

\section{Radial brick vault}

Execution of this kind of arch is done through two parallel centering ribs. One of the centering ribs is inserted at the beginning and the other one is inserted to a depth equal to that of concave. Here, the brick layers are horizontally put and are continued towards the shelves of the arch. For example, if a $20^{\star} 20^{\star} 5$ centimeters brick is used, in the front sight a $20 \star 5$ centimeters brick will be seen (Soldier arrangement) [21]. 
Table 1: Brick arrangement in the three methods of masonry ribs implementation

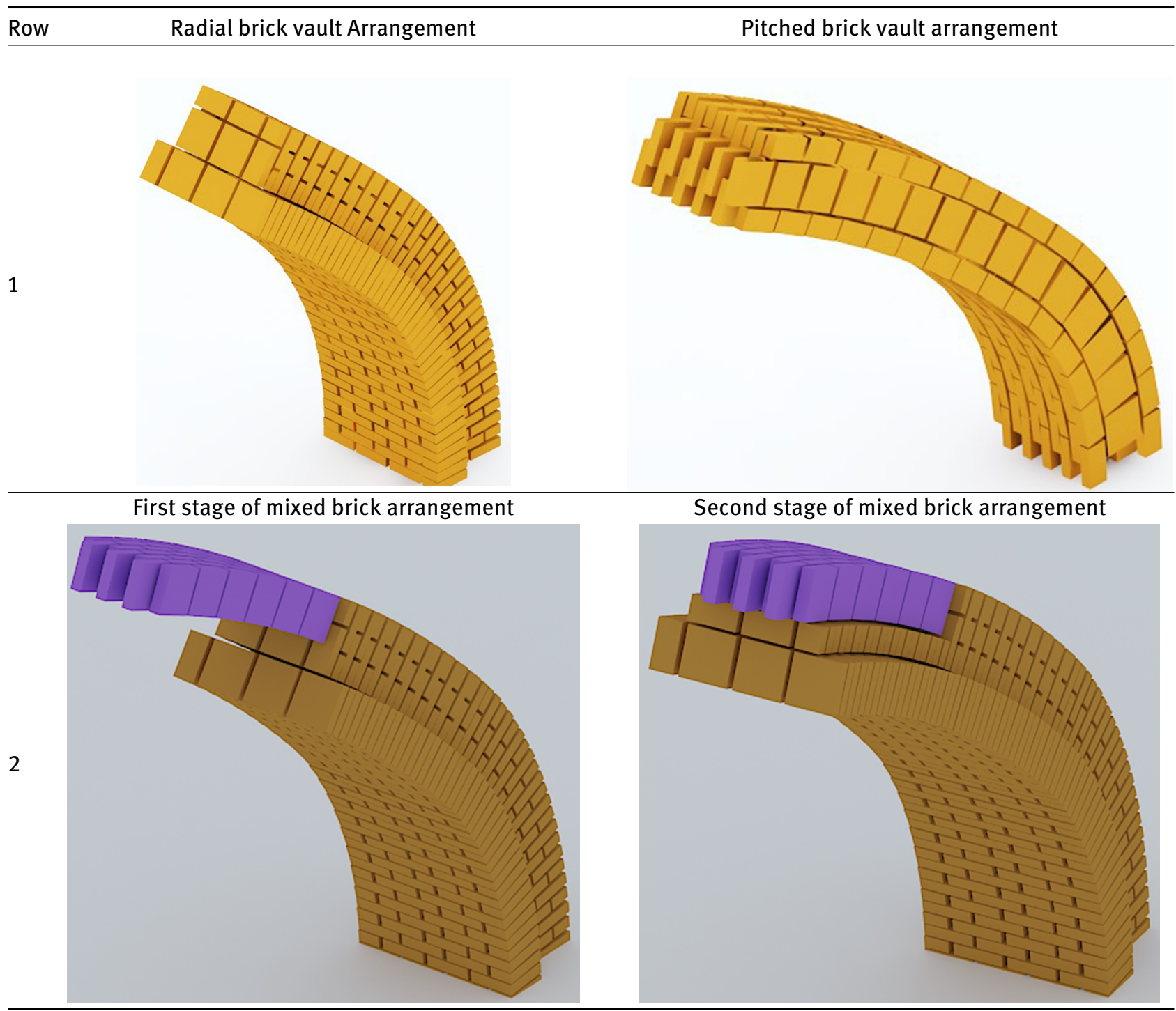

\section{Mixed brick arrangement}

This method is a combination of Roman and barrel method (Table 1, row 2).

\subsubsection{Masonry ribs in radial brick vault arrangement method}

Such type of masonry rib is implemented using two parallel gypsum ribs. Gypsum rib is placed in the beginning and the other one is placed inside the rib in ratio of the depth. After that the work implementation starts on the pier or wall from both sides [3]. In this implementation method, molding under arch is usually used. The bricks rows are continued in the both sides of the masonry rib in the same way that have been laid out on the piers and they are locked at the top roof. It is in a way that for arranging the first row and to create skewback and more interlocking, the bricks are placed in L-shape (Kolduni brick) on the mold at the beginning and end of the Karbandi, alternatively (green colored bricks in Table 2, second row) and then their gaps are filled with complete bricks (yellow bricks in Table 2, second row). For laying the second course, a brick quarter is used at the beginning and end of the masonry rib (red colored bricks in the Table 2, second row) and then the gaps among them are filled with half brick (brown bricks in the Table 2, second row). These two courses are repeated in the next stages in order to reach the arch apex. After finishing the work gypsum ribs are removed and then the masonry rib is completed. 
Table 2: Perspective and photos of some samples of masonry rib implementation with radial brick vault arrangement method

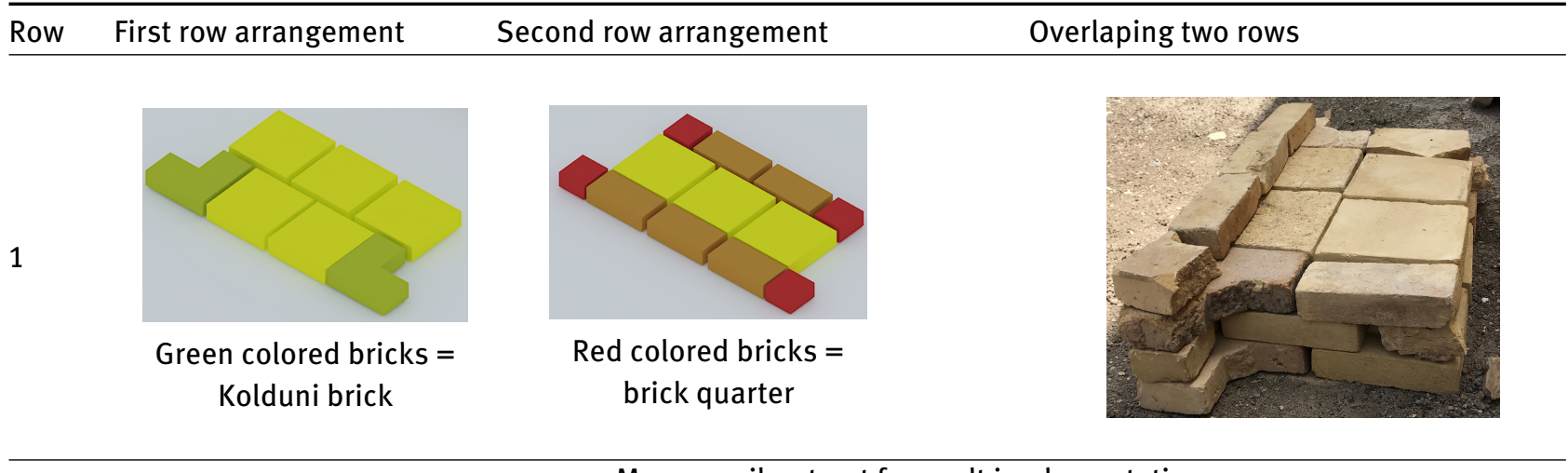
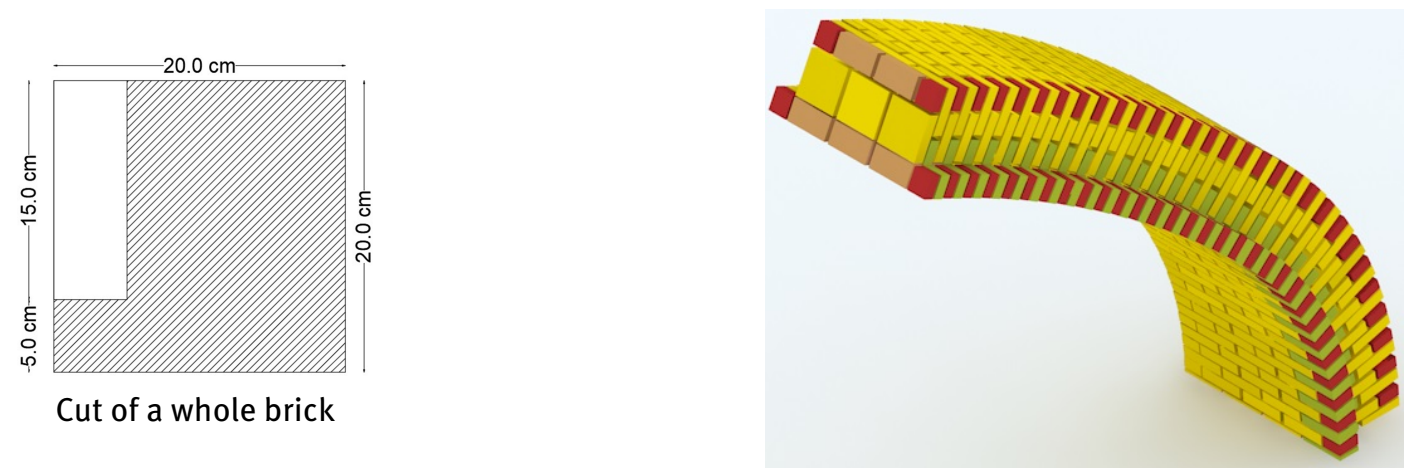

Implementation method of masonry rib with radial brick vault arrangement (one of the facades of Tabriz Bazaar -Tarbiyat St.)

(Ref. the authors 2018).

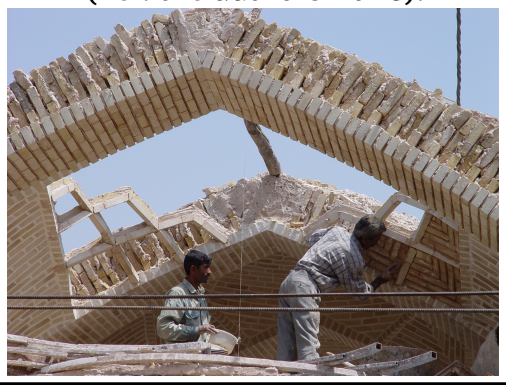

Masonry rib arrangement with radial brick vault arrangement-Sorkhab bazaar of Tabriz (Ref. the authors 2017).

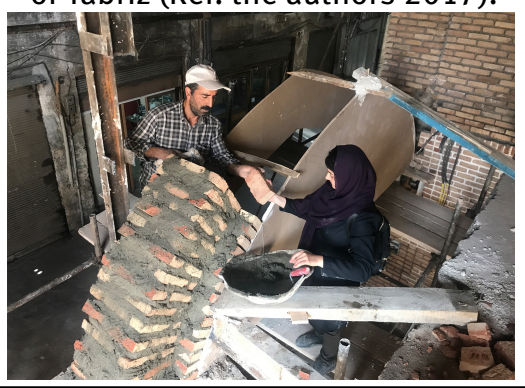

\subsubsection{Masonry rib in pitched brick vault Implementation method}

In pitched brick vault method, the constructor enjoys higher speed of act. Pitched brick vault method alongside gypsum centering is used in the larger opening. Firstly, a plaster rib in size of the masonry rib bay $(10 \mathrm{~cm}$ in thickness) is made on the ground and then it is installed on the work and after that the bricks are placed on them. Using square bricks of $20 \mathrm{~cm}^{\star} 20 \mathrm{~cm}{ }^{\star} 5 \mathrm{~cm}$, both sides of the masonry ribs are constructed in the same manner [12]. Hence, the bricks on the two pillars are made asymmetrically. The implementation method is as follows: the prefabricated rib is placed in the underlying point, then using plaster mortar the bricks are laid out from surrounding long side of the work parallel with the rib in a way that first row is arched then the next rows are laid out parallel to them. A brick of $20 \mathrm{~cm}^{\star} 20 \mathrm{~cm}$ is seen in the front view. In the inner part of the vault the size of $5 \mathrm{~cm}^{\star} 20 \mathrm{~cm}$ is seen as vertical to perpendicular line. In what follows, two different implementation methods are explained with barrel brick arrangement method.

First method: firstly, a row of half brick is placed in the masonry rib centering for skewback in a way that brick 
length is in continuation of the masonry rib (brown bricks of Table 3, row 1). Then, in the back, one row of pitched brick vault arrangement with complete square bricks is implemented and then it is covered again with complete brick in a way that bricks' bonds are not overlapped. After implementation of the first row, the next rows of one side of back layer of the first row is stuck for supporting (yellow bricks of Table 3, first row).

Second method: after placement and implementation of the centering in the pier edge based on the applied geom- etry, the first row of the masonry rib is laid out on the centering with half bricks $\left(20 \mathrm{~cm}^{\star} 10 \mathrm{~cm} \star 5 \mathrm{~cm}\right)$ (green bricks of Table 3, second row). This gives a valuable help to delicacy and beauty of the overall karbandi (such applied geometry and its elements) which is seen at the end from lower angle. The second row is implemented on the first row by pitched brick vault method (brown colored bricks in the table) and again half brick is used in the third row. Finally, half brick is employed in pitched brick vault method as a bearing to

Table 3: Perspective and photo of some examples of masonry rib implementation method with pitched brick vault brick arrangement method

Row Perspective of masonry rib implementation with pitched brick vault brick arrangement based on the first method-one of the vaults of Bidabad Bazaar of Isfahan (Ref. Isfahan Cultural Heritage Archive)

1

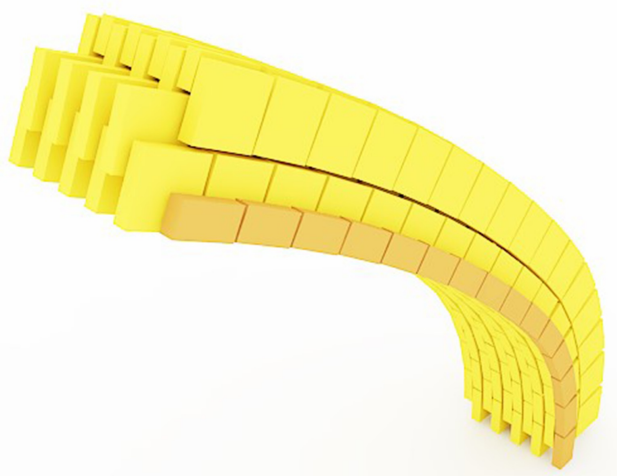

Brown bricks $=$ Half bricks with pitched brick vault method arrangement for creating skewback

Implementation of pitched brick vault arrangement with complete brick based on the second method

1
Masonry rib implementation with pitched brick vault arrangement based on the first method-one of the vaults of Bidabad Bazaar of Isfahan (Ref. Isfahan Cultural Heritage Archive)
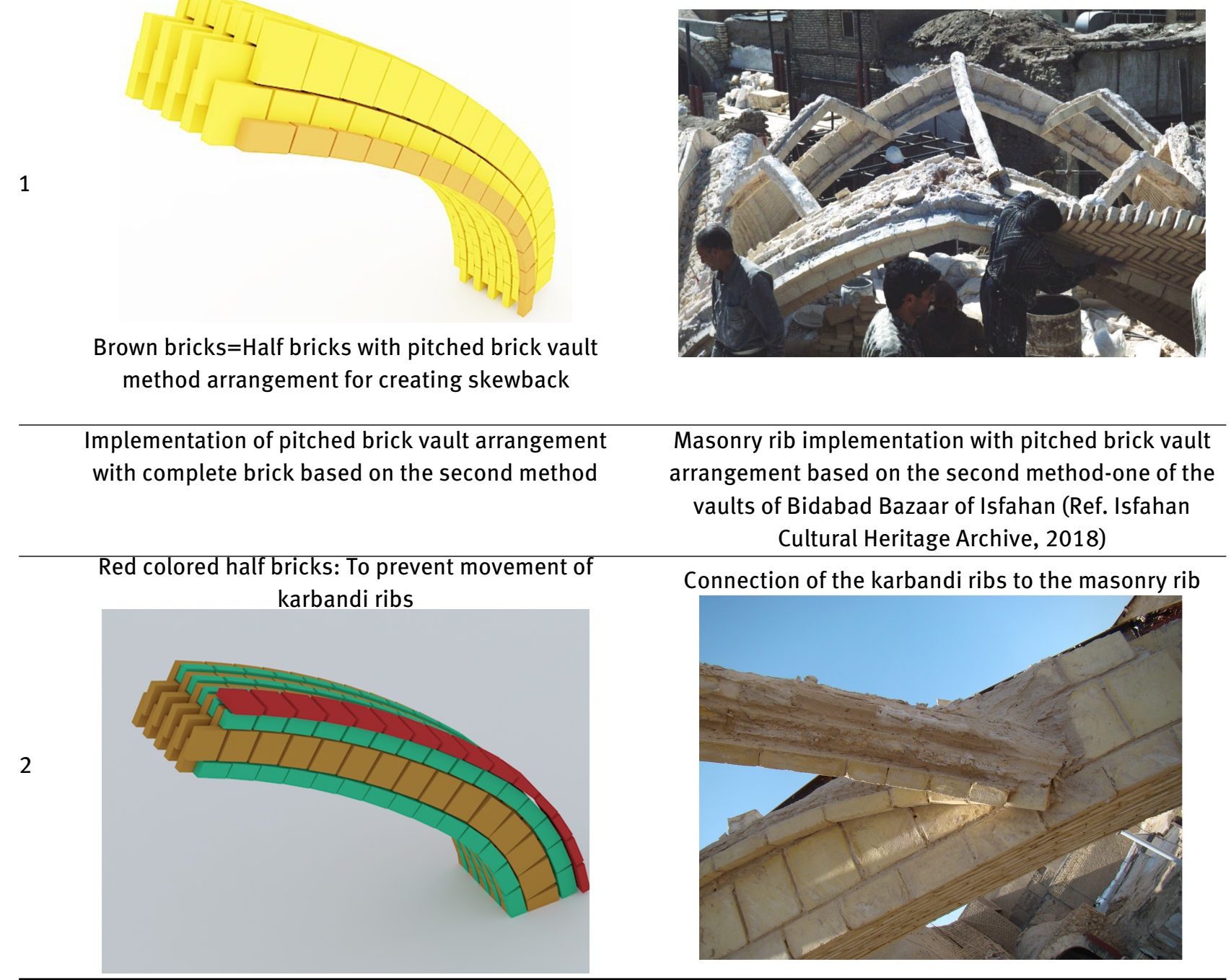
prevent karbandies rib movements (red colored bricks in the Table 3, the second row).

\subsubsection{Combination of radial brick vault and pitched brick vault arrangement}

In some cases a combination of radial brick vault and pitched brick vault methods is used to strengthen and improve load bearing ability in vault implementation especially in implementation of load bearing masonry ribs.
This integrated mixed method, in its turn, is divided into two classes of hidden and explicit.

\subsubsection{Hidden mixed rib}

One of the main reasons of using hidden method is employment of capabilities of radial brick vault arrangement and eliminating its deficits with pitched brick vault arrangement. Such a masonry rib brick arrangement method takes place both with complete and half a brick. The difference between such method and explicit mixed method

Table 4: Perspective and photo of implementation of masonry rib with mixed brick arrangement method in Tabriz

Row Brick arrangement of the masonry rib first row $\quad$ Brick arrangement of the masonry rib second row

1
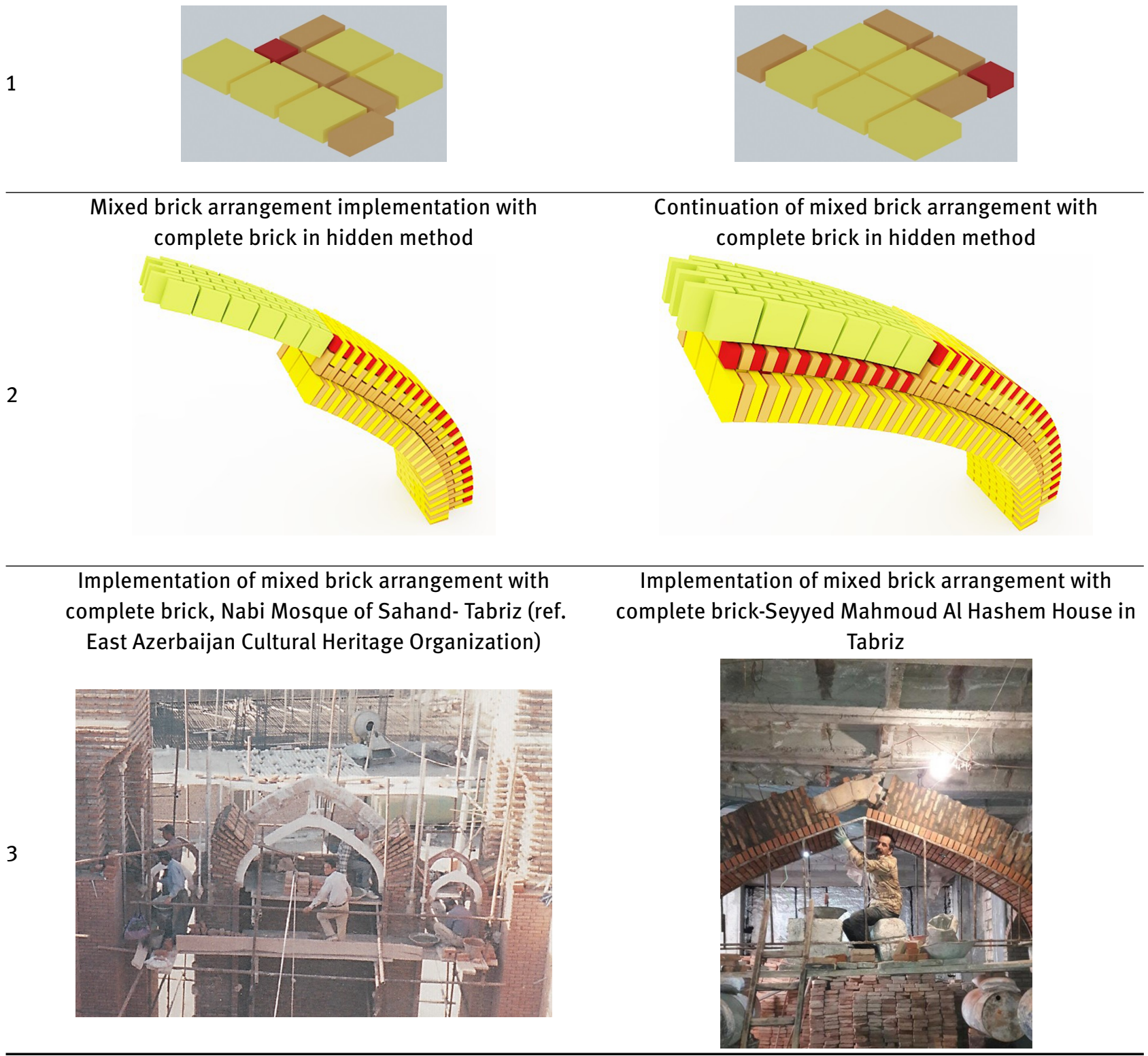
is that beneath the masonry rib is only seen in radial brick vault shape and those bricks laid out in pitched brick vault method are not seen [18]. In the hidden method the masonry rib core is implemented in pitched brick vault method, then it is surrounded by radial brick vault implementation. By doing so the masonry rib becomes thick and very rigid, being resistant to different types of imposed pressures [20]. Firstly the work is filled with radial brick vault arrangement from both sides so that no brick stays on the previous one due to inclination angle, gliding at last. Then in $1 / 6$ of the masonry rib bay (a degree of 22.5 degrees with horizon), the brick arrangement is changed from radial brick vault to pitched brick vault. With some degrees of retreat from the work edge, the masonry rib center is implemented by pitched brick vault arrangement in order to form a continuous row. Then for stability of the work, several rows are created in the two sides in pitched brick vault method [17]. In this stage of construction the masonry rib is at stiffening stage. For façade building façade brick is implemented on it (Table 4).

\subsubsection{Explicit mixed masonry rib method}

Like hidden method in the explicit method, also, firstly the bricks are made in radial brick vault method until half of the two columns. Brick arrangement is implemented with radial brick vault method until $1 / 6$ of the bay and thereafter the implementation continues with pitched brick vault arrangement method, so that several thin brick rows implemented in pitched brick vault method are made on the centering to complete the masonry rib (green colored bricks of
Table 5). This method is not used in implementation of karbandi.

\subsection{Three methods of masonry ribs construction}

(1) connecting the rib into upper part of the masonry rib

(2) connecting the rib to lower part of the masonry rib

If the karbandi base plan is stretched rectangle, then the major part of the ribs are connected to upper part of the masonry rib and transfer the load (Table 5, row 1). If the karbandi base is simple or square, then the ribs are mostly connected to half bricks of lower part of the masonry rib (Table 5, row 2).

\subsection{Intersection manner of the karbandi ribs}

In the octagonal karbandi the ribs are not intersected, however in most karbandies the ribs are intersectional. Firstly, one of the ribs which is more central is processed. For side ribs two statuses are assumed: 1-intersection is in a way that cuts the second rib, in other words both sides of the side rib are isolated, being connected to the other rib of karbandi by mortar or Mitered joint connection (Figure 3). In the second case, side rib bricks are not cut rather they find tongue and groove form and the two ribs are intersected. This is less frequently used method (Figure 4).

Table 5: Perspective and photo of masonry rib implementation using explicit mixed method

\begin{tabular}{llr}
\hline Row First row arrangement & Perspective & $\begin{array}{c}\text { Bridge bay in Chaghazanbil town } \\
\text { of Khuzestan province (2008) }\end{array}$ \\
\hline
\end{tabular}

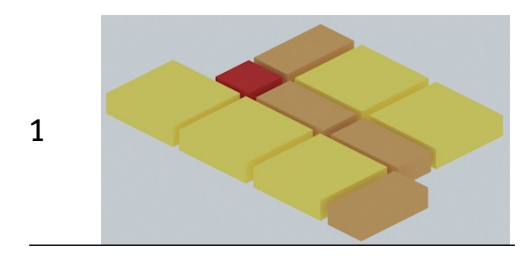

Second row arrangement

2

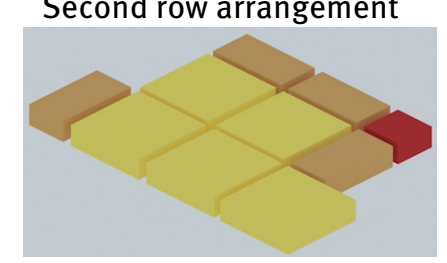

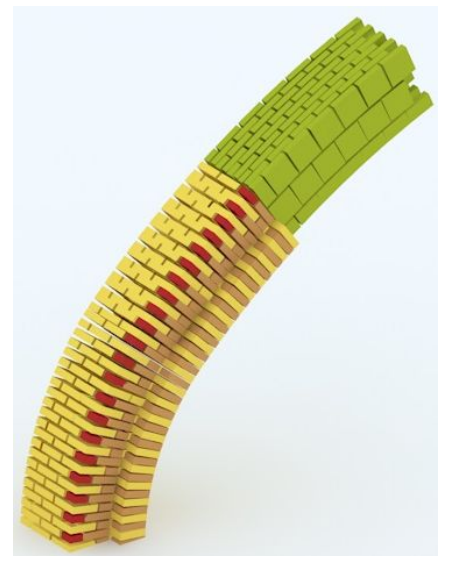


Table 6: Placement manner of Karbandi ribs on the masonry rib

\begin{tabular}{|c|c|c|}
\hline Row & $\begin{array}{c}\text { Connection of the rib to upper part of the masonry rib } \\
\text { in Bidaabad bazaar of Isfahan (Ref. Cultural Heritage } \\
\text { Organization of Isfahan Province) }\end{array}$ & $\begin{array}{l}\text { Perspective of rib placement manner on } \\
\text { the masonry rib }\end{array}$ \\
\hline
\end{tabular}

1
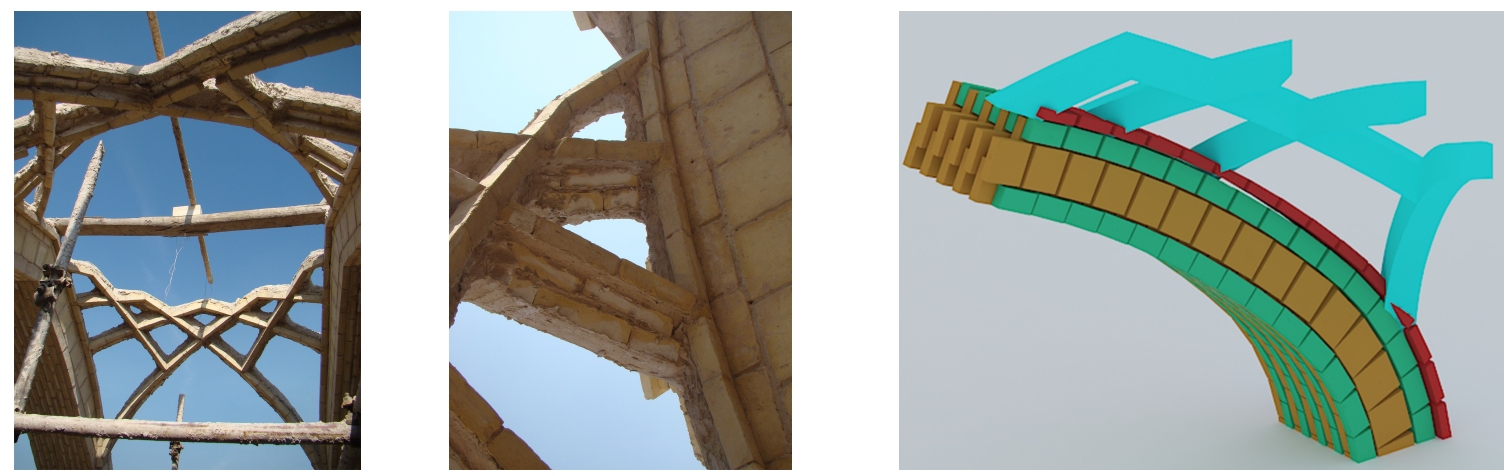

Rib connection to lower part of the masonry rib in bazaar of Isfahan (ref. Cultural Heritage Organization of

Perspective of rib placement manner in the lower part of the masonry rib Isfahan Province)
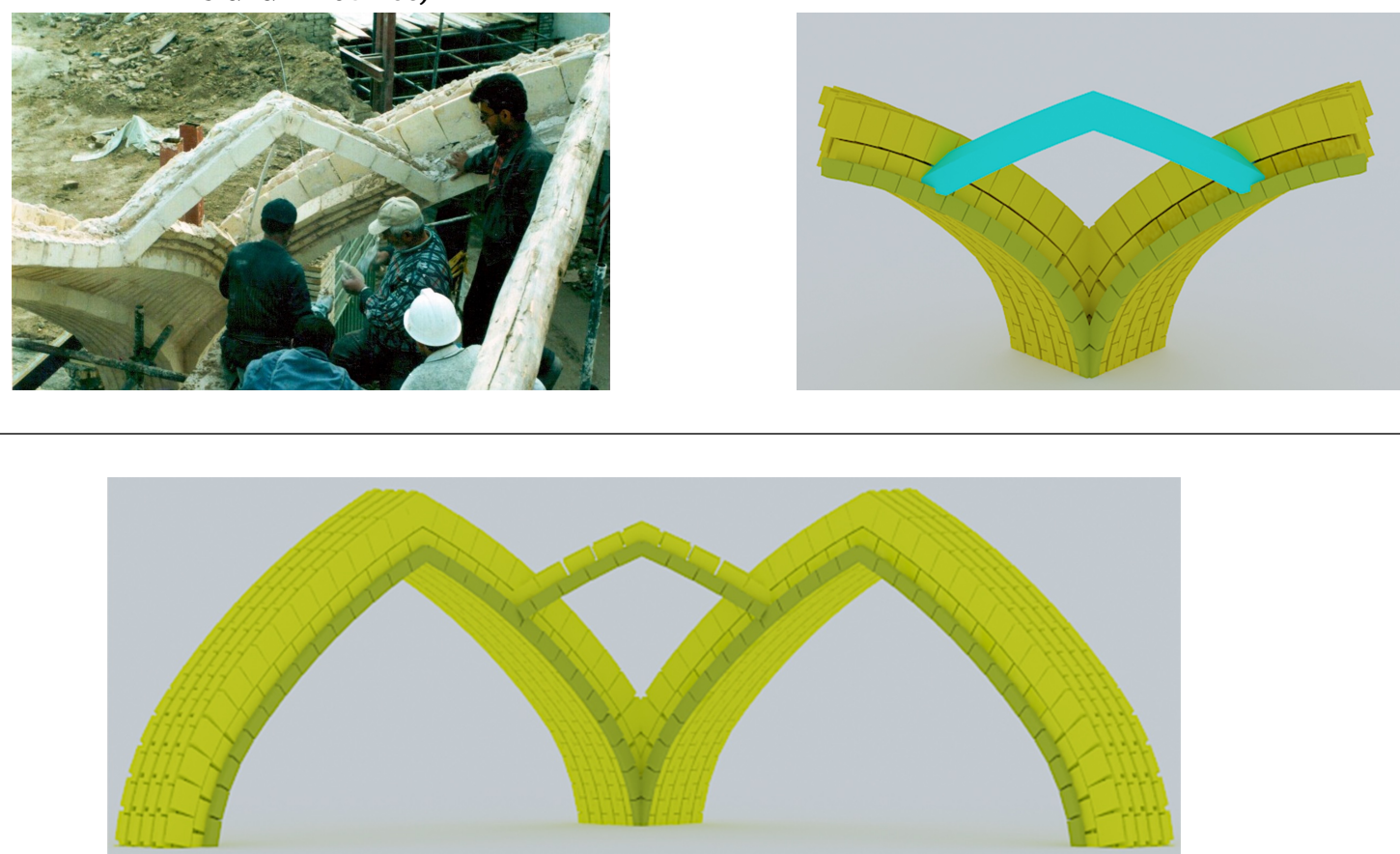

Ribs' connection method to the masonry ribs of karbandi (Source: authors)

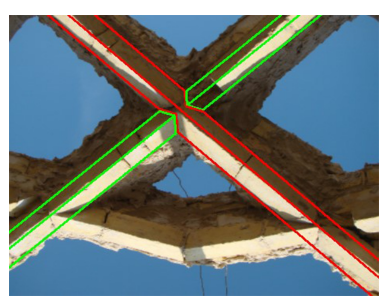

Figure 3: Karbnadi's main and side rib bricks connection with discrete Mitered joint method

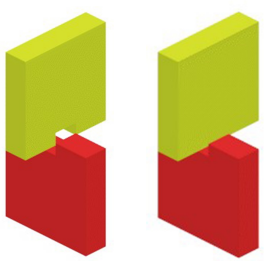

Figure 4: Karbnadi's main and side rib bricks connection with tongue and groove method 


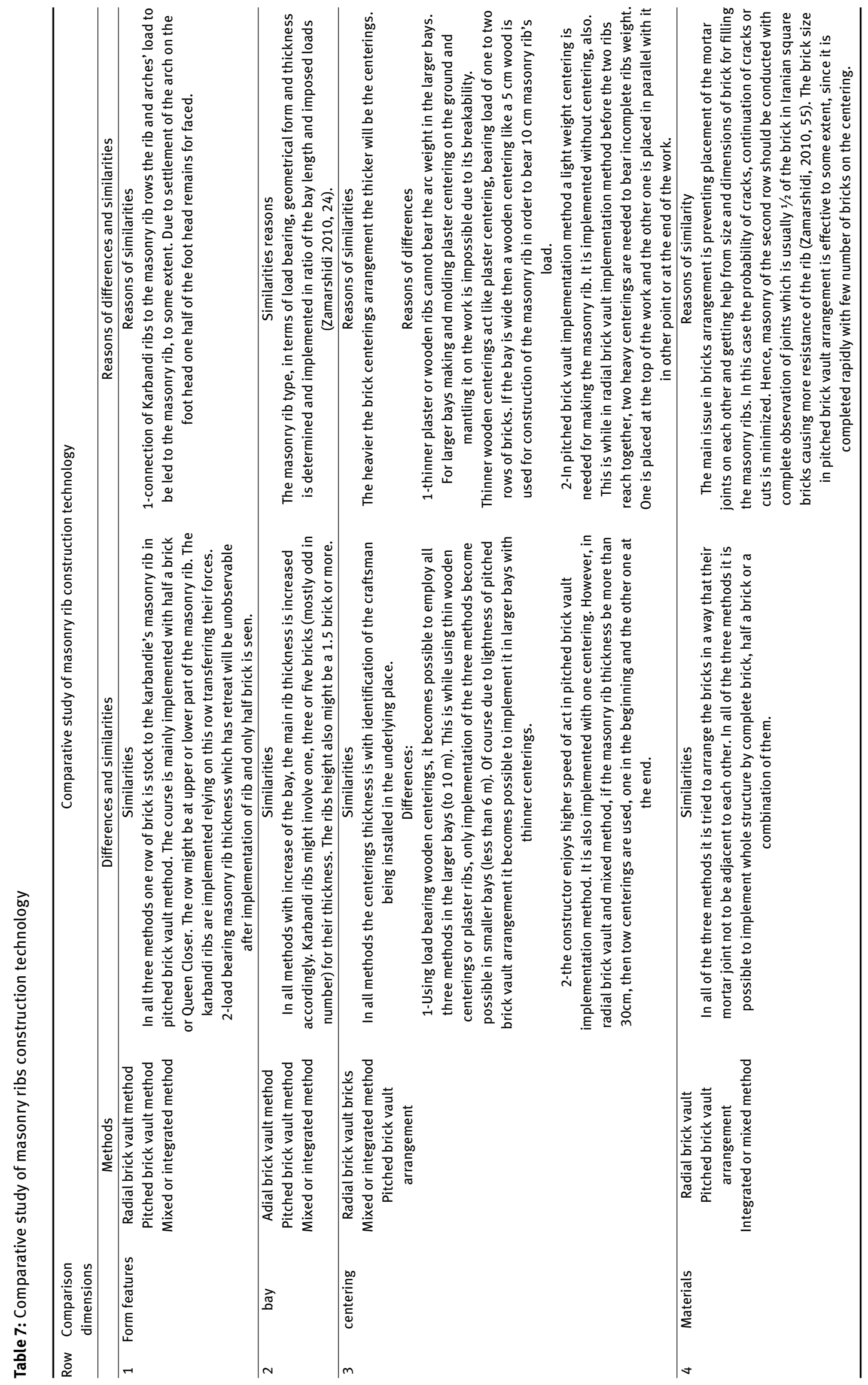




\section{Conclusion}

This article was first to employ traditional craftsmen as oral resources of traditional architecture to focus on different details of karbandie's masonry ribs. In this research, karbandie's masonry ribs are divided into three classes based on their brick arrangement manner (radial brick vault, pitched brick vault and Mixed method). Although all of them used the same similar element for implementation, they have different load resistance and power in ratio of type of their arrangement.

In all methods for complete placement of the vault, ribs or façade in lower part or on the masonry rib needs a support with dimensions of half in half brick. The larger the main bay and the more the imposed load, the thicker will be the masonry rib. After implementation of the first row the next rows are added with the architect's comment for thickening the masonry rib. Those masonry ribs receiving the main load are thicker.

Mixed method has more resistance than other methods and it enjoys more skills for implementation. Since in this method thin brick row implemented in pitched brick vault method whether in hidden or explicit form plays the role of frame for the masonry rib preventing the vault collapse until completion of the work. Mixed method is used in the vaults with larger or middle bays due to enjoying higher resistance.

In the masonry ribs with radial brick vault arrangement, Kolduni bricks are used for creating more interlocking joints (green bricks of Table 2, second row).

Using thinner wooden centering or plaster centering all three methods can be implemented in the small bays. However, in the larger bays (more than 6 meters) radial brick vault arrangement is not employed using such centerings. However, using thicker wooden or metal centering (more than $5 \mathrm{~cm}$ ), all three methods can be used in larger bays.

Karbandi ribs are connected in upper or lower part of the masonry rib in mitered joint method. Moreover, connection of the main and side ribs bricks is mostly implemented by mitered joint and tongue-and-groove methods.

\section{References}

[1] Mehdizadeh F., Tehrani F., ValiBeig N., Applying the 'Hanjar'triangles in the mathematical calculation, implementation and enforcement of traditional Iranian architecture, Maremat-E Asar \& Baft-Haye Tarikhi-Farhangi, 2011, 1, 15-26.
[2] Tehrani F., Tavakoli A., Explain executive techniques proven effective in enhancing resistance of vault, Andishe memari, 2013, 1, 39-53.

[3] Memarian G.H, Persian Architecture: Niaresh, Naghme-ye Noandish Press, Tehran, Iran, 2012.

[4] Dimitri R., Tornabene F., A parametric investigation of the seismic capacity for masonry arches and portals of different shapes, Engineering Failure Analysis, 2015, 52, 1-34.

[5] Lorenzis L.D., Dimitri R., Tegola A.L., Reduction of the lateral thrust of masonry arches and vaults with FRP composites, Construction and Building Materials, 2007, 21, 1415-1430.

[6] Lorenzis L.D., Ochsendorf J., Dimitri R., Structural study of masonry buttresses: the stepped form, Proceedings of the Institution of Civil Engineers: Structures and Buildings, 2012, 165(9), 499-521, 483-498.

[7] Hejazi M., Moayedian S. M., Daei M., Structural Analysis of Persian Historical Brick Masonry Minarets, Journal of Performance of Constructed Facilities, 2015, 30(2).

[8] Hejazi M., Jafari F., Structural Effects of Brick Arrangement and Span Length on Mid-Pointed Arches, Advanced Materials Research, 2010, 133-134: 411-416.

[9] Valibeig N., Mohammadi H., Geometry and Bonding Rules Position Analysis in the Formation of Traditional Iranian Architectural Brick Facades, Nexus Network Journal Architecture and Mathematics, 2016, 18, 467-479.

[10] Zamarshidi H., Dome and elements of architectural coverings in Iran, Zaman Press, Tehran, 2010.

[11] Besenval R., Technique of vaults in ancient East, Habibi, M. trans, 1 ed. Vol. 1 \& 2. Iranian Cultural Heritage Organization, Tehran, 2000.

[12] Golombek L., Wilber D., The Timurid Architecture of Iran and Turan, Princeton University Press, 1988.

[13] Petralla S., Arches and Ribbed Vaults of the Iranian Tradition, Type presented at the online Proceedings of the International Symposium Masons at Work, Architecture and Construction in the Pre-Modern World, 2012.

[14] Wilber D., The masjid- I Atiq of Shiraz, Afranbak trans , Academy of Art, Tehran, Iran, 2008.

[15] Godard A., Iranian vaults, Afsar, K. trans, Farhangsara Press, Tehran, 1990.

[16] Tehrani F., Beyond the geometry of vault and dome, Sofeh, 1992, 6-8, 33-54.

[17] Mehdizadeh F., Tehrani F., ValiBeig N., Practical geometry in the construction of Iranian brick barrel vault, 2012.

[18] Dadkhah E., ValiBeig N., Geometric study on construction technology of masonry ribs in Isfahan Jame Mosque, Type presented at the Research conference architecture and urbanism islamic history of iran, 2017.

[19] Raeisi M., Bemanian M., Tehrani F., Rethinking the Concept of Karbandi Based on theoretical geometry, practical geometry and building function, Maremat \& Me'mari-e Iran 3, 2013, 5 , 33-54.

[20] Pirnia M. K., Bozorgmehri Z., Hendese Dar Memari (Geometry in Architecture). Sazman-e Miras-e Farhangi-ye Keshvar (Iranian Cultural Heritage Organization) (in Farsi), Tehran, 2006.

[21] Nikandish G., Daneshmandi A., The recognition of rib development in Persian architecture, 2014.

[22] Fallahfar S., Dictonary of Iranian traditional Architecture, Tehran, Iran, 1999. 


\section{Footnotes}

\section{Brick dimensions}

Table A1: Formation of different types of brick with different dimensions obtained from complete square-shaped brick

\begin{tabular}{|c|c|c|c|}
\hline Row & Name & Dimensions ratio & Shape \\
\hline 1 & $\begin{array}{l}\text { In English=Whole } \\
\text { In Persian=Tamam }\end{array}$ & $\begin{array}{c}a=5 \mathrm{~cm} \\
4 a * 4 a * a\end{array}$ & \\
\hline 2 & $\begin{array}{l}\text { In English }=\text { Half } \\
\text { In Persian=Nime }\end{array}$ & $\begin{array}{c}a=5 \mathrm{~cm} \\
4 a * 2 a * a\end{array}$ & \\
\hline 3 & $\begin{array}{l}\text { In English }=\text { Quarter } \\
\text { In Persian }=\text { Charak }\end{array}$ & $\begin{array}{c}a=5 \mathrm{~cm} \\
2 a * 2 a * a\end{array}$ & \\
\hline 4 & $\begin{array}{l}\text { In English=Three-Quarter } \\
\text { In Persian=Se-charak }\end{array}$ & $\begin{array}{c}a=5 \mathrm{~cm} \\
3 a * 2 a * a\end{array}$ & \\
\hline 5 & $\begin{array}{l}\text { In English=Queen Closer } \\
\text { In Persian=Qalamdany }\end{array}$ & $\begin{array}{l}a=5 \mathrm{~cm} \\
4 a^{*} a * a\end{array}$ & \\
\hline
\end{tabular}

Karbandi ribs: Karbandi ribs are parts, one or two feet of which are placed on the masonry rib or on other ribs of karbandi.

Araghchin: From the highest point of intersecting ribs to the apex of the arch is filled with a hemispherical or $1 / 4$ spherical shape. This part is called Araghchin.

Fillers: The various forms that occur at intervals arise from the intersection of the karbandi ribs.-sckewback: starting point of roof, vault and dome [22].

mitered joint : is a joint made by beveling each of two parts to be joined, usually at a $45^{\circ}$ angle, to form a corner, usually a $90^{\circ}$ angle [22].

tongue-and-groove: Retreat and bulge of two parts, involvement of which causes connection of the two parts, being widely used in making wooden objects such as latticed doors and windows [22]. 